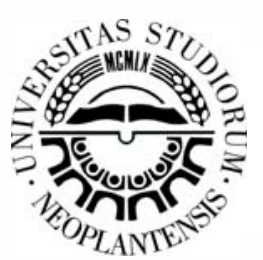

\title{
Developing and Testing Hybrid Glass to Steel Structural Elements - Flexible Design Approach
}

\author{
Bojana Trajanoska, * Viktor Gavriloski, Elisaveta Doncheva
}

Ss. Cyril and Methodius University in Skopje, Faculty of Mechanical Engineering, Skopje, Macedonia

\begin{abstract}
Structural integrity of elements depends on their geometry, function and connections used between them. In this paper new hybrid glass to steel elements are investigated concerning their mechanical behavior and function which directly influences their design and vice versa. Their basic design is tested experimentally and then a flexible design approach including parametrical study is proposed for developing unique structural elements for different application. The concept design takes advantage of the mechanical properties of tempered glass, steel and polymer adhesive and achieves structural geometry which results in high mechanical, structural and architectural potential.
\end{abstract}

Key words: hybrid elements, glass and steel, design, concept, structural integrity;

\section{INTRODUCTION}

The geometry of structural elements, their function and connections used between them are the main three factors in gaining structural integrity in construction. The appearance and the behavior of a structure depend on the geometry and mechanical characteristics of the used materials.

Structural glass is a brittle isotropic material that is mainly used in construction for its transparency as an infill element in building `s facade. However, today glass is known to be vital part of structures even as a bearing element. This comes as result of revolutionary changes in the processes of production, including glass product dimensions and forms as well as larger use of strengthening processes and laminated structures of glass panels. [1] All of these transformations are made with one cause of changing the mechanical behavior of the glass and make it more suitable for a structural element that can accept and transmit loads without compromising its integrity.

This paper presents new approach in designing hybrid structural element consisting of three different materials that acts as layered composite providing changed structural behavior of the element as whole. The concept design takes advantage of the mechanical properties of tempered glass, steel and polymer adhesive and achieves structural geometry which results in high mechanical, structural and architectural potential.

\section{DESIGN CONCEPT OF HYBRID EEMENTS}

Glass, under normal temperatures of service behaves as a linear elastic material that will break when tensile stresses exceed a critical value. But the most prominent characteristic of glass as a structural element is its brittleness causing the glass elements to collapse suddenly, without any residual post-failure strength due to the brittle way of fracturing and its propagation through the whole element. [2] On the other hand, good compressive strength of the glass allows for including connection elements with greater strength and hardness, like steel.

When using point support and bolted connections in connecting glass elements, stress concentrations occur, which demand using additional elements with appropriate mechanical characteristics able to accept and transfer stresses toward bearing structure providing more even stress distribution in the brittle element.

Greatest designers` challenge when working with glass elements is overcoming tensile strength as well as postbreakage behavior deficiency especially when it comes to glass planar elements. Other than known laminated design, other investigated design approach is to reinforce the overall structural capacity by adding a supporting layer or lamination. This can be done by combination of two materials developing a structural composite: individual or doubled glass plate and reinforcing steel layer [3]. The reinforcing layer could be used to enhance the load bearing

* Corresponding author's.e-mail: bojana.trajanoska@mf.edu.mk 
capacity of the planar element or to introduce more plasticity in the structural behavior of the glass element and to enhance the post-breakage behavior of laminated glass [4]. The metal layer is added to the glass element usually perforated in order to provide certain level of transparency of the structural element. However, the use of standard perforated metal sheets although are adding to the load bearing capacity of the glass element, it is also reducing glass transparency and due to its standard formats of perforation it is limiting the architectural expression.

The presented hybrid elements in this paper consist of a single glass pane adhesively reinforced by a non-standard perforated stainless-steel sheet added in the tension zone of the structural element. This design results in layer composite element which provides added value in structural integrity by overcoming the brittleness of the glass, gaining post-breakage capacity and certain transparency level. All of these characteristics are among other factors (discussed in this paper) dependent on the perforation geometry which allows for free element design potential as well.

\section{DEVELOPING ANDTIESTING THE HYBRIDEEMENTS}

The new proposed concept of hybrid elements includes single tempered glass panel and thin perforated sheet (layer) of steel that form a laminated structure where the bond between laminates is made by means of adhesive and not the usual interlayer polymer materials used in producing laminated glass (PVB, EVA etc.).

The perforated metal layer is located at the tensile zone of the glass panel bonded with adhesive along the surface of the glass panel (Fig. 1). In this way, the reinforcement is achieved in the weakest zone of the panel where tensile stresses occur under out of plane bending. The used surface type of bonding allows for laminate effect of the structure and ensures composite action of the element.

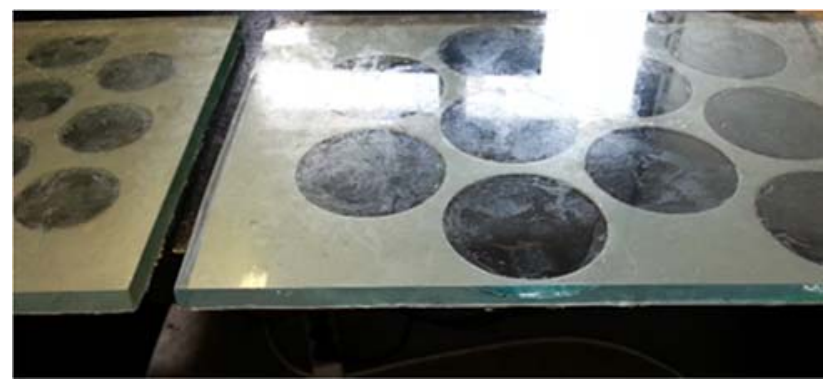

Fig. 1. Small scale models of the hybrid elements representing its structure (glass - adhesive - steel)

With the purpose of defining the mechanical characteristics and the reinforcement capacity, the new element underwent an experimental testing. Under standard fourpoint bending test, the structure is loaded with out of plane force which is distributed to the elasto-plastic perforated steel sheet that has a capacity of accepting higher stresses than the glass (Fig. 2).

Unified perforation of parallel grid of circle forms is used for the presented and tested models. The used glass pane in the hybrid models is made of fully tempered glass with experimentally defined bending strength of $200 \mathrm{MPa}$. The other two glass characteristics relevant for this testing are its Young's modulus of $70000 \mathrm{MPa}$, which does not change with the glass thermal treatment, and Poisson's coefficient of 0,22. Steel reinforcement used in the models is made out of stainless steel with tensile strength of a 550 MPa. The surface bond to the metal layer to the glass panel is made by structural adhesive type DC3145 which is silicon based. [6]

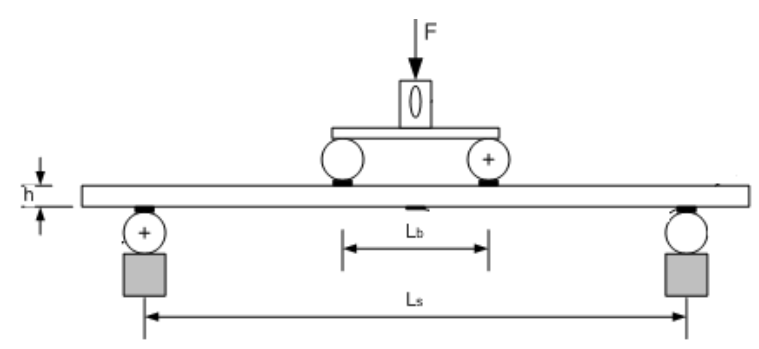

Fig. 2 Experimental setup of four point bending

Evaluation of the mechanical properties of the elements is done in two phases. In the first phase, flat glass panes with the defined dimensions were tested, for evaluating the bending stiffness of a single tempered glass pane.

Considering probability for surface flaws that can influence the strength of the element, several specimens where tested.[5] In the second phase of the testing, hybrid elements consisting of glass panel with $10 \mathrm{~mm}$ of thickness and a bonded reinforcement with circle forms of $60 \mathrm{~mm}$ in diameter were tested. The setup of testing the reinforced elements is shown in Fig. 3.

In order to identify and define the post-breakage behavior, the testing was done until full element failure (Fig. 4).

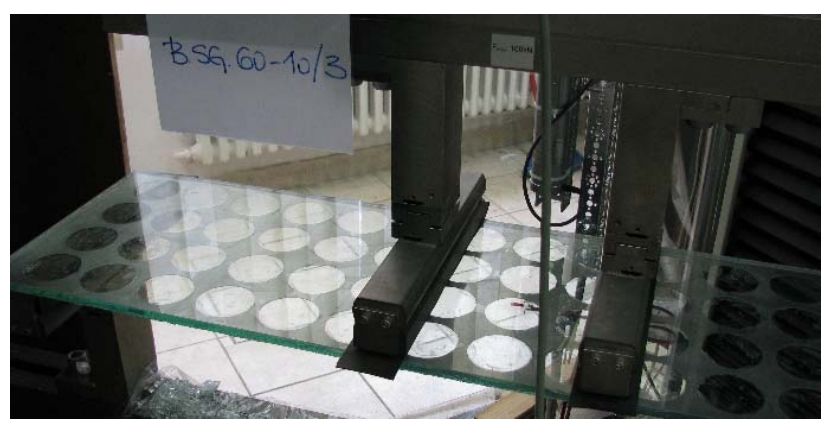

Fig. 3. Experimental setup for hybrid element

\section{DISCUSSING RESULTS}

The goal of the experimental testing was defining the composite action of the structural elements through measurable variables and observe the changes in the mechanical behavior of the new element as result of the included reinforcement. The composite action was defined by measuring the bending strength of the hybrid models. The standard used for the experimental testing defines the bending strength of the tested element by means of the maximal force of failure for the glass elements, and force 
at first crack for the hybrid elements (crack of glass pane). Thus, as results of this experimental testing a force deflection curves were gained and analyzed for the tested models (Fig.5)

Result force-deflection curves show existent residual strength of the structural element since the force magnitude increases again after the appearance of first crack, failure of the glass panel.

Different parameters influence the results of the testing, including manual technology of applying the adhesive, thus different thickness of the adhesive along the surface of the elements, production flaws on the surface of the glass elements and edge conditions which is seen through deviation in results for different specimens of the hybrid model.

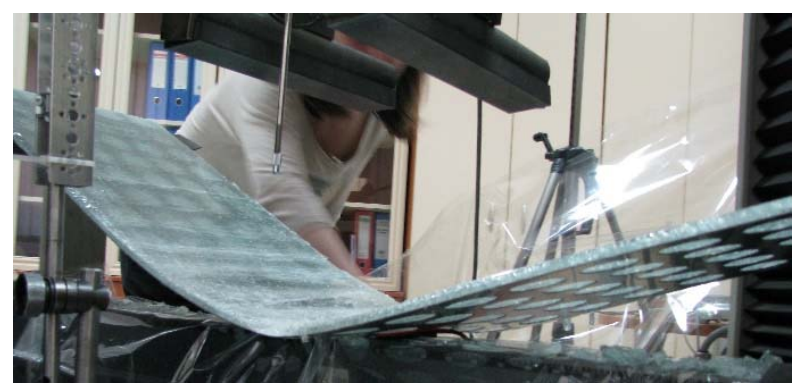

Fig. 4. Full hybrid element failure

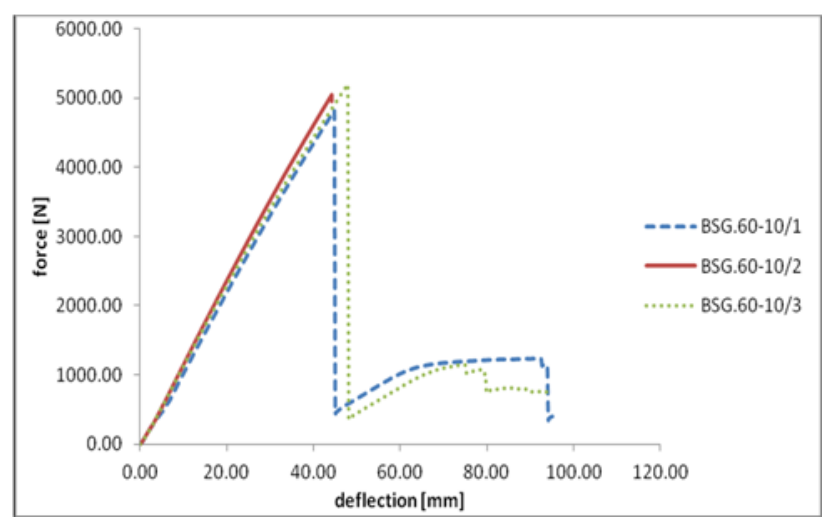

Fig. 5. Force-deflection curves for hybrid models $(d=60 \mathrm{~mm})$

The second specimen showed no post-breakage capacity and collapsed fully, quickly after glass panel failure.

Defining the influence of the perforation size was made by testing other set of element specimens with circle forms of $40 \mathrm{~mm}$ in diameter. Comparative analysis shows different mechanical behavior of the hybrid elements depending on reinforcement layer perforation size (Fig. 6).

Reinforced hybrid elements that use uniform perforation with smaller sized forms show greater increase in bending strength of the elements.

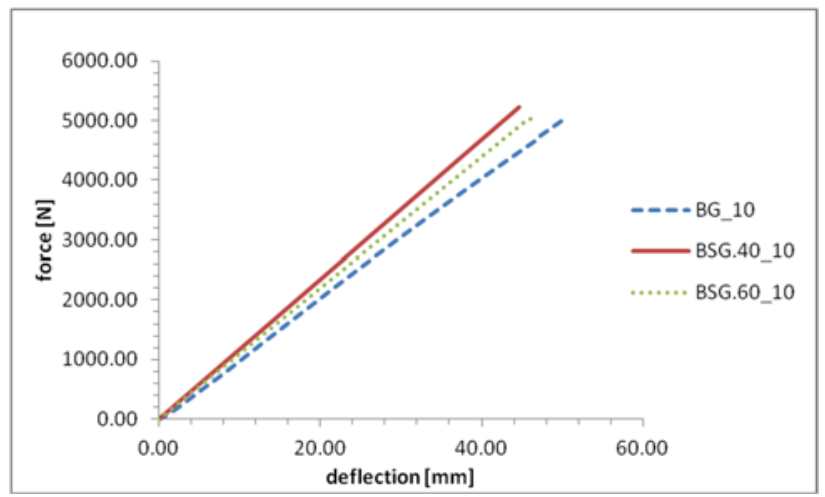

Fig. 6 Comparative force-deflection curves

\section{DIFERENT DESIGN APPROACH}

As stated before, the main factor influencing the mechanical properties of the new model is the perforation forms size. Having this in mind, a different design approach was investigated.

Namely, a parametrical analysis using finite element modeling was performed observing the influence of the perforation size and geometry on stress distribution in the glass panel under different element support conditions (Fig.7).

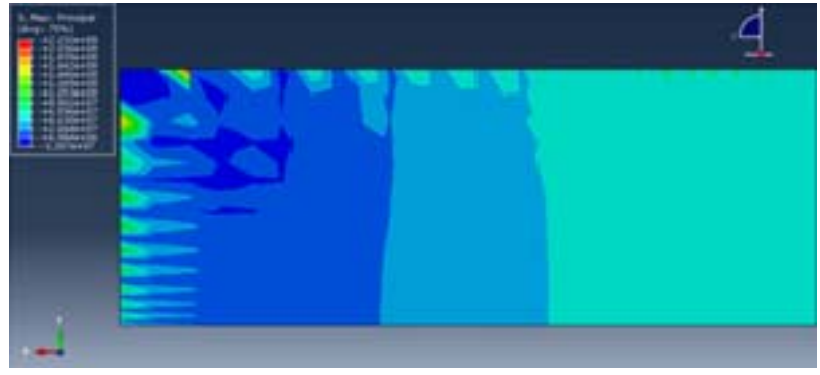

Fig. 7. Stress distribution in glass panel - 4 nodes support tension zone

After defining the stress state of a glass pane under specific support and out of plane load, results were used to design perforation geometry and size. Different design concepts were gained using perforation form changer (Fig. 8). At the last stage of the numerical analysis, structural stress analysis was made, this time using the perforation element and the change in glass panel stress distribution was observed, as part of the modeled hybrid element.

Great change in stress distribution can be observed from the graphical preview of the models with four nodes support. The stress concentration near the supports is the biggest problem. As we can see from the results, these concentrations cannot be seen in the tensioned zone of the composite because the distribution of the stresses is more uniform. That is the side where reinforcement is applied with specific perforation forms (Fig. 9). 


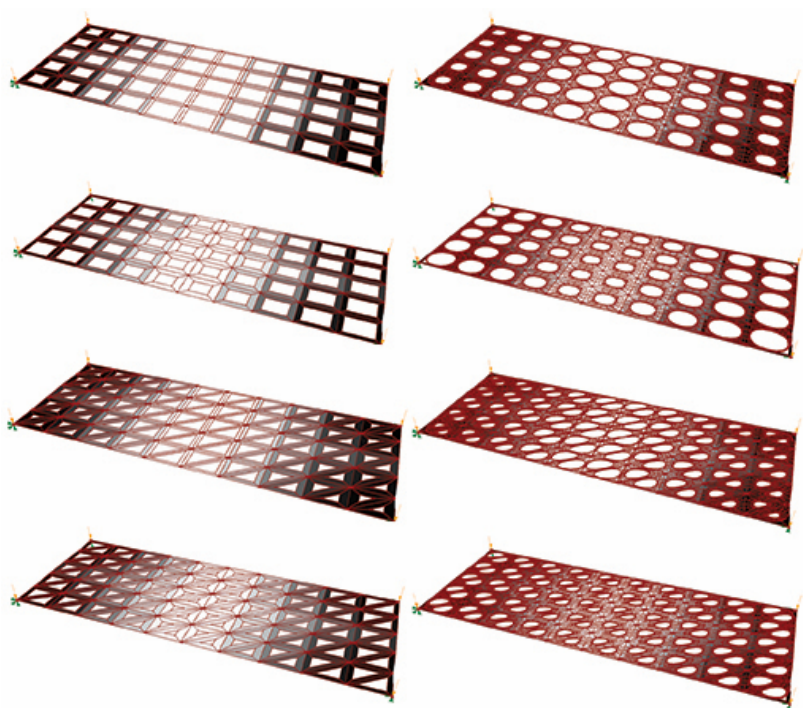

Fig. 8. Different perforation design concepts

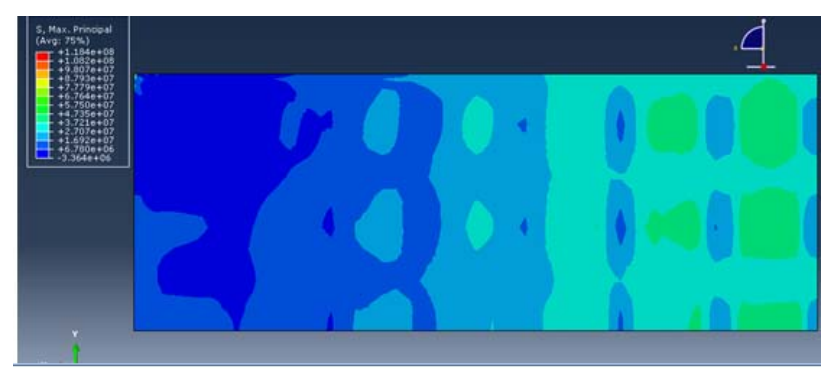

Fig. 9. Stress distribution in glass panel - 4 nodes support tension zone (hybrid element)

\section{Conclusion}

Structural integrity of an element is defined by its geometry and material properties. Using tempered glass that has no residual strength provides structural element that will collapse as soon as critical failure strength of glass is reached. Due to tempered glass breakage pattern, laminating this type of glass is one way of dealing with the problem, but usually in more than two glass panes or combination of glass types which increases the total weight of the structural element.

Another possible approach of solving the problem of post breakage behavior is applying reinforcement which has a ductile properties. Steel is this kind of material, which is used for forming hybrid glass elements concepts in form of laminated structures. This form of reinforcement allows for composite action which changes the mechanical behavior of the element and increases its overall mechanical strength. The resulting hybrid elements are using the material properties advantage of a perforated steel layer with thickness of $1 \mathrm{~mm}$ to act as reinforcement layer giving residual strength to a tempered glass panel by means of adhesive bonding to the glass elements tension zone and at the same time not compromising the overall transparency of the glass.

The perforation type of the reinforcement layer influences the mechanical characteristics of the hybrid element and thus providing design potential for achieving unique and different element depending on its function in the structure. The parametrical analysis for defining the perforation shapes and size can be upgraded with additional deciding variables that can influence the design of the concept including light transmition, transparency capacity, structural element support type etc.

\section{REFERENCES}

[1] Haldimann M., Luible A., Overend M.: Structural use of Glass. 2007.

[2] Belis, J., Van Impe, R., Vanlaere, W., Lagae, G. Buffel, P. and M. De Beule: Glass Structures and Plasticity: Contradiction or Future?, Key Eng. Mater., vol. 274-276, pp. 975-980, 2004.

[3] Feirabend, S. and Sobek, P. W.: Improved postbreakage behavior of laminated glass due to embedded reinforcement, Glass performance days 2009, pp. 726-729, 2009.

[4] Nhamoinesu, S.: Steel-Glass Composite Structures (thesis), 2014.

[5] Veer F.A: The strength of glass, a nontransparent value, Heron, vol. 52, no. 1-2, pp. 87-104, 2007.

[6] Trajanoska B, Gavriloski V, Bogatinoski Z., Zdraveski F.: Glass - steel hybrid elements under four point bending test, Journal of Applied Engineering Science, 13(2015), pp.141 - 146, 2017. 